\title{
Article \\ Facile Synthesis of Carbon- and Nitrogen-Doped Iron Borate as a Highly Efficient Single-Component Heterogeneous Photo-Fenton Catalyst under Simulated Solar Irradiation
}

\author{
Shan-Yuan Hsiao, En-Xuan Lin and Pei-Yuin Keng *(D) \\ Department of Materials Science and Engineering, National Tsing Hua University, Hsinchu 300, Taiwan; \\ edwardhsiao16888@gmail.com (S.-Y.H.); a5483892@gmail.com (E.-X.L.) \\ * Correspondence: keng.py@gapp.nthu.edu.tw
}

check for updates

Citation: Hsiao, S.-Y.; Lin, E.-X.; Keng, P.-Y. Facile Synthesis of Carbonand Nitrogen-Doped Iron Borate as a Highly Efficient Single-Component Heterogeneous Photo-Fenton Catalyst under Simulated Solar Irradiation. Nanomaterials 2021, 11, 2853. https://doi.org/10.3390/ nano11112853

Academic Editor: Joaquim Esteves da Silva

Received: 7 October 2021

Accepted: 21 October 2021

Published: 26 October 2021

Publisher's Note: MDPI stays neutral with regard to jurisdictional claims in published maps and institutional affiliations.

Copyright: (c) 2021 by the authors. Licensee MDPI, Basel, Switzerland. This article is an open access article distributed under the terms and conditions of the Creative Commons Attribution (CC BY) license (https:/ / creativecommons.org/licenses/by/ $4.0 /)$.

\begin{abstract}
The development of a heterogeneous catalyst for use in environmental remediation remains a challenging and attractive research endeavor. Specifically, for Fenton reactions, most research approaches have focused on the preparation of iron-containing heterostructures as photo-Fenton catalysts that utilize visible light for enhancing the degradation efficiency. Herein, the synthesis and novel application of $\mathrm{C}, \mathrm{N}$-doped iron borates are demonstrated as single-component heterogeneous photo-Fenton catalysts with high Fenton activity under visible light. Under the optimal conditions, $10 \mathrm{mg}$ of the catalyst is shown to achieve effective degradation of $10 \mathrm{ppm}$ methylene blue (MB) dye, Rhodamine B (RhB) dye, and tetracycline (TC) under simulated solar irradiation with a first-order rate constant of $\mathrm{k}=0.218 \mathrm{~min}^{-1}, 0.177 \mathrm{~min}^{-1}$, and $0.116 \mathrm{~min}^{-1}$, respectively. Using MB as a model system, the $\mathrm{C}, \mathrm{N}$-doped iron borate exhibits 10 - and 26 -fold increases in catalytic activity relative to that of the $50 \mathrm{~nm}$ hematite nanoparticles and that of the non-doped iron borate, respectively, in the presence of $\mathrm{H}_{2} \mathrm{O}_{2}$ under the simulated solar irradiation. Furthermore, the optimum reaction conditions used only 320 equivalents of $\mathrm{H}_{2} \mathrm{O}_{2}$ with respect to the concentration of dye, rather than the several thousand equivalents of $\mathrm{H}_{2} \mathrm{O}_{2}$ used in conventional heterogeneous Fenton catalysts. In addition, the as-prepared $\mathrm{C}, \mathrm{N}$-doped iron borate achieves 75\% MB degradation after $20 \mathrm{~min}$ in the dark, thus enabling the continuous degradation of pollutants at night and in areas with poor light exposure. The stability and recyclability of $\mathrm{C}, \mathrm{N}$-doped iron borate for the oxidation of MB was demonstrated over three cycles with insignificant loss in photo-Fenton activity. The high Fenton activity of the $\mathrm{C}, \mathrm{N}$-doped iron borate is considered to be due to the synergistic action between the negatively-charged borate ligands and the metal center in promoting the Fenton reaction. Moreover, carbon and nitrogen doping are shown to be critical in modifying the electronic structure and increasing the conductivity of the catalyst. In view of its synthetic simplicity, high efficiency, low cost of reagents, and minimal cost of operation (driven by natural sunlight), the as-prepared heterogeneous single-component metal borate catalyst has potential application in the industrial treatment of wastewater.
\end{abstract}

Keywords: photo-Fenton reaction; iron borate; dye degradation; tetracycline; Rhodamine B; azo dyes; metal borates; photocatalysts; dopant

\section{Introduction}

The development of a facile, effective, low-cost, stable, and non-toxic water treatment process is becoming a critical issue in the 21st century due to the drastic increases in population, urbanization, and industrialization. Modern industrialization produces by-products and pollutants that have adverse effects upon human health, the environment, and aquatic life. Hence, many innovative methodologies have been applied to the removal of contaminants from waste water, including coagulation, precipitation, electrolysis, sedimentation, ion exchange, and adsorption [1]. However, these physical separation methods fail to completely degrade the pollutants and, thus, produce secondary waste products that are 
discharged into the environment. Advanced oxidation processes (AOPs) are regarded as highly effective methods for degrading most wastewater pollutants into smaller, non-toxic compounds such as carbon dioxide [2,3]. The AOPs rely on the generation of reactive oxygen species (ROS) in the presence of oxidizing species such as $\mathrm{H}_{2} \mathrm{O}_{2}$ and peroxymonosulfate (PMS). However, the conventional AOP process utilizes oxidizing reagents in large excess $(\sim 1000 \times)$ with respect to the concentration of pollutants, thus increasing the overall cost of water treatment [4].

Among the various AOP processes, the Fenton reaction has received the most intensive research attention due to its rapid reaction rate, high mineralization efficiency, low cost of operation, easy-to-handle reagents, and the use of non-toxic and earth abundant iron oxides to activate $\mathrm{H}_{2} \mathrm{O}_{2}$. Recent advances include the introduction of electrons to the heterogeneous Fenton catalyst by combination with semiconducting, electron-rich, or plasmonic materials in order to accelerate the rate-limiting step (i.e., the reduction of $\mathrm{Fe}$ (III) to the redox active $\mathrm{Fe}(\mathrm{II})$ ion) in the decomposition of $\mathrm{H}_{2} \mathrm{O}_{2}$ [5]. Other physical-assisted strategies such as the introduction of an electric field [6], UV/visible light [7,8], ultrasound, and microwave radiation $[9,10]$ have also shown an increase in the generation of hydroxyl radicals, and therefore exhibited a high degradation efficiency under external fields. Notably, the combination of iron oxides with a wide bandgap semiconductor such as $\mathrm{TiO}_{2}$ and $\mathrm{ZnO}$ has provided heterogeneous photo-Fenton catalysts with significant improvements over the use of iron oxides alone because the photogenerated electrons facilitate the conversion of $\mathrm{Fe}(\mathrm{III})$ to $\mathrm{Fe}(\mathrm{II})[11,12]$. Moreover, the highly positive valence bands of $\mathrm{TiO}_{2}$ and $\mathrm{ZnO}$ provide highly oxidative photogenerated holes that can also participate in the degradation of organic pollutants $[13,14]$. However, the large bandgaps of these semiconductors limit them to the use of UV light, thus increasing the cost of operation. Hence, researchers have combined iron-containing materials with lower bandgap semiconductors such as CdSe, $\mathrm{C}_{3} \mathrm{~N}_{4}$, and $\mathrm{BiVO}_{4}$ in order to generate photocarriers under visible light irradiation and, thus, take advantage of the freely-available and unlimited solar energy [15-17]. However, while this is an elegant approach, the large-scale implementation of these iron-containing heterojunctions and heterostructures is hampered by the complicated multi-step chemistry required to synthesize them. Therefore, the development of single component Fenton catalysts that possess a large absorbance in the visible light region and simultaneously exhibit high activity toward $\mathrm{H}_{2} \mathrm{O}_{2}$ activation remains an important research endeavor. However, the design of an effective Fenton catalyst requires several key considerations, including the cost of the materials and the cost of operation, along with the degradation efficiency, toxicity, and stability of the catalyst. Various iron-based nanomaterials such as iron oxide, sulfide, carbide, and composite materials have also been explored as potential strategies for enhancing Fenton catalysis [5]. However, to the best of the present authors knowledge, iron borate $\left(\mathrm{FeBO}_{3}\right)$ has never been investigated as a photo-Fenton catalyst.

Iron borate is a rhombohedral calcite-type crystal with interesting magnetic, magnetooptical, magneto-acoustic, and resonance characteristics [18-20]. There has been renewed interest in the family of metal borates due to their peculiar performance in electrocatalytic water-splitting reactions [21,22]. While the exact mechanism of these reactions remains controversial, it is generally thought to be based on the sacrificial role of the borate ligand in donating electrons to the metal center to provide a more favorable electrochemical route. In Fenton catalysis, an electron-rich metal center also facilitates the conversion of $\mathrm{Fe}(\mathrm{III})$ to the redox-active $\mathrm{Fe}$ (II) species, thus enhancing $\mathrm{H}_{2} \mathrm{O}_{2}$ decomposition. However, to the best of the present authors' knowledge, the metal borates have not been explored previously as photo-Fenton catalysts for environmental remediation. Hence, based on the promising approach of modulating the electronic structures, conductivities, and active sites of various redox-based catalysts via doping with small heteroatoms such as carbon and nitrogen [23-27], a novel $\mathrm{C}, \mathrm{N}$-doped $\mathrm{FeBO}_{3}$ is presented herein as an excellent photo-Fenton catalyst for activating $\mathrm{H}_{2} \mathrm{O}_{2}$ under visible light irradiation. In practical application, the as-prepared catalyst exhibits pseudo first-order kinetics with an apparent rate of $0.218 \mathrm{~min}^{-1}$ for the degradation of methylene blue (MB) using only 320 equivalent excess of $\mathrm{H}_{2} \mathrm{O}_{2}$. Compared 
to the non-doped $\mathrm{FeBO}_{3}$, the $\mathrm{C}, \mathrm{N}$-doped $\mathrm{FeBO}_{3}$ exhibits a 26-fold increase in $\mathrm{MB}$ dye degradation efficiency. It is considered that the present results could open up research opportunities into the family of iron borates for Fenton reactions.

\section{Materials and Methods}

\subsection{Preparation of the $\mathrm{C}, \mathrm{N}$-Doped Iron Borate}

The C,N-doped iron borate was prepared via a low-temperature annealing method. Briefly, boric acid ( $3.138 \mathrm{~g}, 0.050 \mathrm{~mol})$, guanidine hydrochloride $(1.617 \mathrm{~g}, 0.017 \mathrm{~mol})$, and hexamethylenetetramine $(0.2375 \mathrm{~g}, 0.002 \mathrm{~mol})$ were dissolved in distilled water $(63 \mathrm{~mL})$ at room temperature. The precursor mixture $(12.6 \mathrm{~mL})$ and various amounts of 50-nm $\mathrm{Fe}_{3} \mathrm{O}_{4}$ nanoparticles $(50,100$, and $150 \mathrm{mg}$ ) were then added to a crucible and sonicated for $30 \mathrm{~min}$ at room temperature. Subsequently, the mixture was heated and kept at $80^{\circ} \mathrm{C}$ in an oven for $24 \mathrm{~h}$ to yield a completely dry solid. The dried solid was then annealed in a furnace at $800{ }^{\circ} \mathrm{C}$ under ambient atmospheric pressure. The heating rate was $5^{\circ} \mathrm{C} \mathrm{min}-1$, and the maximum temperature was maintained for $12 \mathrm{~h}$. The sample was retrieved from the furnace upon cooling down to $90^{\circ} \mathrm{C}$ under atmospheric conditions. Finally, the greenish solid was ground into a powder and stored under ambient conditions. The synthesis of $\mathrm{C}, \mathrm{N}$-doped $\mathrm{FeBO}_{3}$ was repeated for more than 10 times and a typical yield was between determined to be $80-90 \mathrm{mg}$. The obtained $\mathrm{C}, \mathrm{N}$-doped iron borate samples with various amounts of $\mathrm{Fe}_{3} \mathrm{O}_{4}$ nanoparticles are denoted hereafter as the $5 \mathrm{wt} . \%, 10 \mathrm{wt} . \%$, and $15 \mathrm{wt} . \%$ $\mathrm{C}, \mathrm{N}$-doped iron borate, respectively.

\subsection{Characterization}

The particle size, morphology, and chemical composition of the C,N-doped iron borate samples were analyzed using a transmission electron microscope (Jeol, JEMARM200FTH, Tokyo, Japan) equipped with energy dispersive $\mathrm{X}$-ray (EDS) mapping. The X-ray diffraction (XRD) patterns were obtained using a Bruker D2 spectrometer, and the photoluminescence emission spectra were obtained using a Perkin Elmer LS55 spectrometer. The optical absorption measurements were performed via UV-visible diffuse reflectance spectroscopy (UV-DRS; Hitachi, U-3900, Tokyo, Japan). In addition, high-resolution X-ray photoelectron spectroscopy (XPS; ULVAC-PHI, PHI Quantera II, Kanagawa, Japan) was performed using $\mathrm{Al} \mathrm{K} \alpha$ irradiation. For this procedure, the as-prepared powder was centrifuged twice with DI water and ethanol, then drop-coated onto a silicon substrate. The binding energy was calibrated to an adventitious carbon peak at $284.6 \mathrm{eV}$. The XPS peak deconvolution and fitting were performed using the CASA XPS software. In addition, ultraviolet photoelectron spectroscopy (UPS) analysis was performed using a ULVAC-PHI PHI 5000 Versaprobe II with $\mathrm{He} \mathrm{I}(21.22 \mathrm{eV})$ as a photon source with a $5 \mathrm{~V}$ bias. The bonding characteristics of the $\mathrm{C}, \mathrm{N}$-doped $\mathrm{FeBO}_{3}$ samples were examined via Fourier-transform infrared (FTIR) spectroscopy (Bruker Vertex 80v, Billerica, MA, USA). The iron concentrations were measured using an inductively coupled plasma optical emission spectrometer (ICP-OES; Agilent 725, Santa Clara, CL, USA).

\subsection{Photocatalytic Degradation Experiments}

The photo-Fenton reaction of the as prepared $\mathrm{C}, \mathrm{N}$-doped $\mathrm{FeBO}_{3}$ was evaluated by the degradation of methylene blue (MB), Rhodamine $\mathrm{B}(\mathrm{RhB})$, and tetracycline $(\mathrm{TC})$ under a $150 \mathrm{~W}$ solar simulator. MB was used as a model contaminant for optimizing the performance of the $\mathrm{C}, \mathrm{N}$-doped iron borate as a photo-Fenton catalyst. In a typical experiment, the $\mathrm{C}, \mathrm{N}$-doped $\mathrm{FeBO}_{3}$ catalyst $(10 \mathrm{mg})$ was suspended in $\mathrm{MB}$ solution $(40 \mathrm{~mL}, 10 \mathrm{ppm})$, sonicated for $5 \mathrm{~min}$, then stirred for $30 \mathrm{~min}$ to achieve adsorption/desorption equilibrium in the dark. This was followed by the addition of $10 \mathrm{mM} \mathrm{H}_{2} \mathrm{O}_{2}\left(40 \mu \mathrm{L}, 4 \times 10^{-4} \mathrm{~mol}\right)$ and irradiation under a $150 \mathrm{~W}$ solar simulator. During this experiment, $2 \mathrm{~mL}$ kinetic samples were extracted from the solution every $5 \mathrm{~min}$ until the total reaction time reached $20 \mathrm{~min}$. Each sample was centrifuged to remove any residual catalysts from the solution, and the supernatant was collected to determine the concentration of MB using a UV-vis ab- 
sorbance spectrophotometer (HITACHI, U-3900) at their maximum absorbance of $663 \mathrm{~nm}$. The reaction rate was evaluated using a pseudo-first-order kinetics model according to the Langmuir-Hinshelwood formula. The cycling stability of the $\mathrm{C}, \mathrm{N}-$ doped $\mathrm{FeBO}_{3}$ was evaluated by using the same catalyst sample for three consecutive runs of dye degradation. After each run, the $\mathrm{C}, \mathrm{N}$-doped $\mathrm{FeBO}_{3}$ was collected, sonicated with distilled water and ethanol for $10 \mathrm{~min}$, and dried for use in the subsequent reactions. The amount of $\mathrm{MB}$ and hydrogen peroxides in the subsequent runs were adjusted according to the amount of catalyst collected after each run. More detailed protocol is available in the Supplementary Materials.

\subsection{Active Species Analysis}

The main reactive oxygen species (ROS) that were responsible for the MB degradation using the $\mathrm{C}, \mathrm{N}$-doped $\mathrm{FeBO}_{3}$ were evaluated by adding various trapping reagents, namely isopropanol (IPA, $6.1 \mu \mathrm{L}, 1 \mathrm{mM}$ ), ethylenediaminetetraacetic acid disodium salt dihydrate (EDTA-2Na, $26.9 \mathrm{mg}, 1 \mathrm{mM}$ ), and 2,2,6,6-tetramethylpiperidine-1-oxyl (TEMPO, $12.2 \mathrm{mg}$, $1 \mathrm{mM}$ ) to scavenge $\cdot \mathrm{OH}, \mathrm{h}^{+}$, and $\cdot \mathrm{O}_{2^{-}}$, into the $\mathrm{MB}$ degradation experiments. The formation of the hydroxyl radical was confirmed and quantified by adding an excess amount of terephthalic acid (TA; $40 \mathrm{~mL}, 3.3 \mathrm{mg}, 5 \times 10^{-4} \mathrm{M}$ ) and measuring the production of 2-hydroxy terephthalic acid (2-HTA) according to its intense photoluminescence at $430 \mathrm{~nm}$ upon photoexcitation at $332 \mathrm{~nm}$.

\section{Results}

The XRD patterns of the as-prepared $\mathrm{C}$,N-doped $\mathrm{FeBO}_{3}$ samples with various quantities of iron oxide nanoparticles are presented in Figure 1, and are all well matched to that of pure $\mathrm{FeBO}_{3}$ (JCPDS No. 76-0701). Specifically, $\mathrm{FeBO}_{3}$ adopts a calcite crystalline structure that belongs to the rhombohedral space group $\mathrm{R} 3^{-} \mathrm{C}$. The XRD spectra contain no diffraction peaks corresponding to $\mathrm{Fe}_{3} \mathrm{O}_{4}$ or boron carbon oxynitride (BCNO) $[28,29]$, thus indicating that all the Fe and $\mathrm{B}$ species were converted into the $\mathrm{C}, \mathrm{N}$-doped $\mathrm{FeBO}_{3}$ nanocomposite. Moreover, since the XRD patterns of the $\mathrm{C}, \mathrm{N}$-doped $\mathrm{FeBO}_{3}$ do not contain any other impurity peaks and do not exhibit peak broadening or peak shifting, the results demonstrate that the carbon and nitrogen atoms were fully incorporated into the interstitial spacing of iron borate crystal structure.

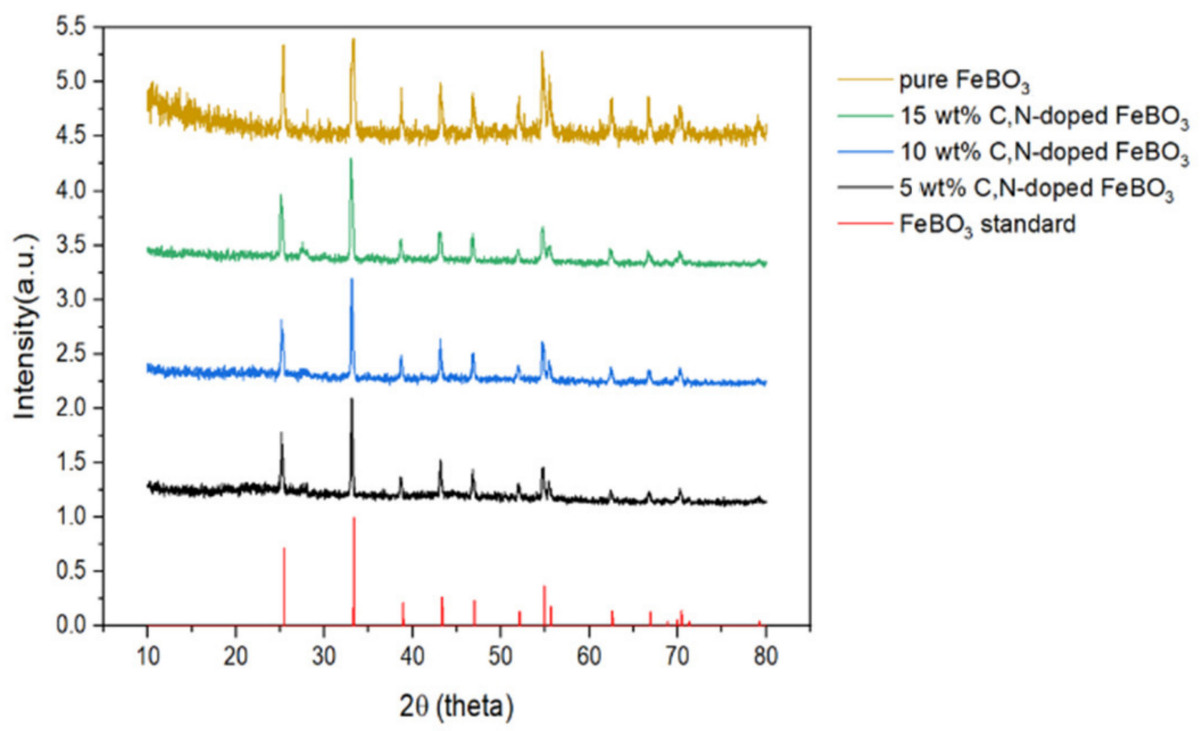

Figure 1. The XRD patterns of the various as-prepared $\mathrm{C}, \mathrm{N}$-doped $\mathrm{FeBO}_{3}$ samples.

The HR-TEM, STEM, and EDX mapping images of the $\mathrm{C}, \mathrm{N}$-doped $\mathrm{FeBO}_{3}$ are presented in Figure 2. Here, the as-prepared $\mathrm{C}, \mathrm{N}$-doped $\mathrm{FeBO}_{3}$ particle is seen to be irregular in shape, with an average size of $197 \pm 32 \mathrm{~nm}(n=13)$. Additionally, the HR-TEM image suggests that the particles are polycrystalline in nature, with a random lattice orientation and an 
interplanar fringe spacing of $0.35 \mathrm{~nm}$ (Figure $2 \mathrm{~b}$, red square), which corresponds to the (012) lattice plane of $\mathrm{FeBO}_{3}$. The elemental mappings in Figure 2d-h indicate that the elements $\mathrm{B}$, $\mathrm{C}, \mathrm{Fe}, \mathrm{N}$, and $\mathrm{O}$ are homogeneously distributed throughout the irregularly-shaped particle, thus confirming the successful doping of the as-prepared $\mathrm{FeBO}_{3}$ with carbon and nitrogen.
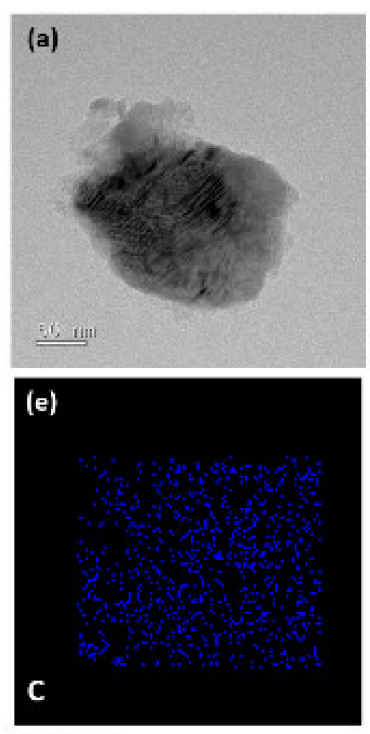

$100 \mathrm{~nm}$
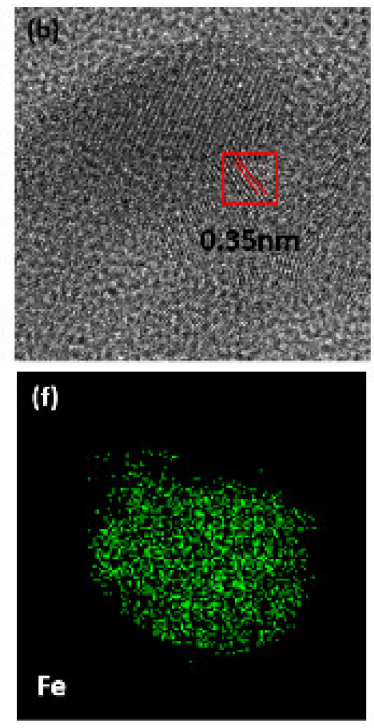

$700 \mathrm{~nm}$
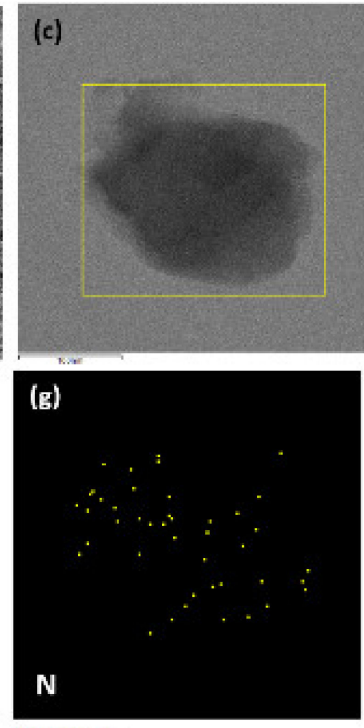

$100 \mathrm{~nm}$
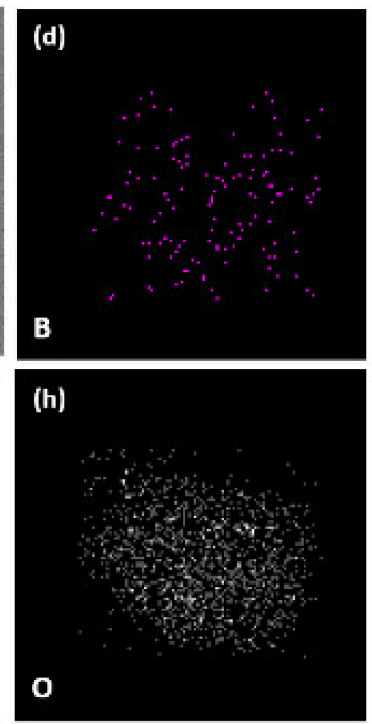

$100 \mathrm{~nm}$

Figure 2. The morphology and chemical composition of the as-prepared iron borate: (a,b) low-resolution (a) and highresolution (b) TEM images; (c) STEM image, and (d-h) corresponding EDX mapping images for the elements B, C, Fe, N, and O. EDX mapping images were taken within the yellow square in Figure 2c.

The FTIR spectrum of the as-prepared $\mathrm{C}, \mathrm{N}$-doped $\mathrm{FeBO}_{3}$ is presented in Figure 3. Here, the characteristic absorption bands of the borate group are observed, including the $\mathrm{B}-\mathrm{O}$ stretching vibration at $1384-1460 \mathrm{~cm}^{-1}$ and the B-O-B stretching vibration at $749-781 \mathrm{~cm}^{-1}$. In addition, the two absorptions at $642 \mathrm{~cm}^{-1}$ and $546 \mathrm{~cm}^{-1}$ in the fingerprint region correspond to the stretching vibrations of $\mathrm{Fe}-\mathrm{O}$ and $\mathrm{Fe}-\mathrm{O}-\mathrm{B}$, respectively [19,30-34]. Further, the broad band at $3200 \mathrm{~cm}^{-1}$ due to the $\mathrm{O}-\mathrm{H}$ and $\mathrm{COOH}$ stretching vibration can be explained by the presence of adsorbed atmospheric water and the formation of formic acid in the presence of iron containing compound, respectively. The formation of formic acid could be due to the decomposition of nitrogen precursors to ammonia and formaldehyde during the thermal annealing reaction in the presence of iron oxides [35]. Subsequently, catalytic oxidation of formaldehyde resulted in the formation of formic acid and carbon dioxide. The signature infrared (IR) bands for these compounds are shown in Figure 3, in which the carboxylic acid O-H stretching is embedded in the broad absorption $\sim 3200 \mathrm{~cm}^{-1}$, while the carbonyl $(\mathrm{C}=\mathrm{O})$ band can be visualized as a shoulder around $1650 \mathrm{~cm}^{-1}$ wavenumber. Moreover, the physisorption of carbon dioxides onto the metal center can be clearly observed at $2350 \mathrm{~cm}^{-1}$ as the asymmetric stretching of $\mathrm{CO}_{2}$ [36,37]. The carbon doping into $\mathrm{FeBO}_{3}$ can also be visualized through the formation of iron carbonyl $(\mathrm{Fe}-\mathrm{C}=\mathrm{O})$ bonding between $1900 \mathrm{~cm}^{-1}$ and $2100 \mathrm{~cm}^{-1}$ (Figure 3). The other distinct IR band at $2500 \mathrm{~cm}^{-1}$ is assigned to the hydride vibration of borane (B-H) [38,39].

The XPS analysis of the as-prepared $\mathrm{C}, \mathrm{N}$-doped $\mathrm{FeBO}_{3}$ is presented in Figure 4. Here, the XPS survey spectrum (Figure 4a) confirms the presence of the elements B, C, N, O, and $\mathrm{Fe}$, with the significant percentage of $\mathrm{C}$ and $\mathrm{N}$ further confirming the successful doping (Table S1). Moreover, compared to the full XPS spectrum of the pure $\mathrm{FeBO}_{3}$ (Figure S1), that of the pure $\mathrm{FeBO}_{3}$ XPS exhibits no nitrogen signal. The residual carbon signal in the XPS as shown in Figure S1 can be explained by the adsorption of carbon dioxide during handling under atmospheric conditions. 


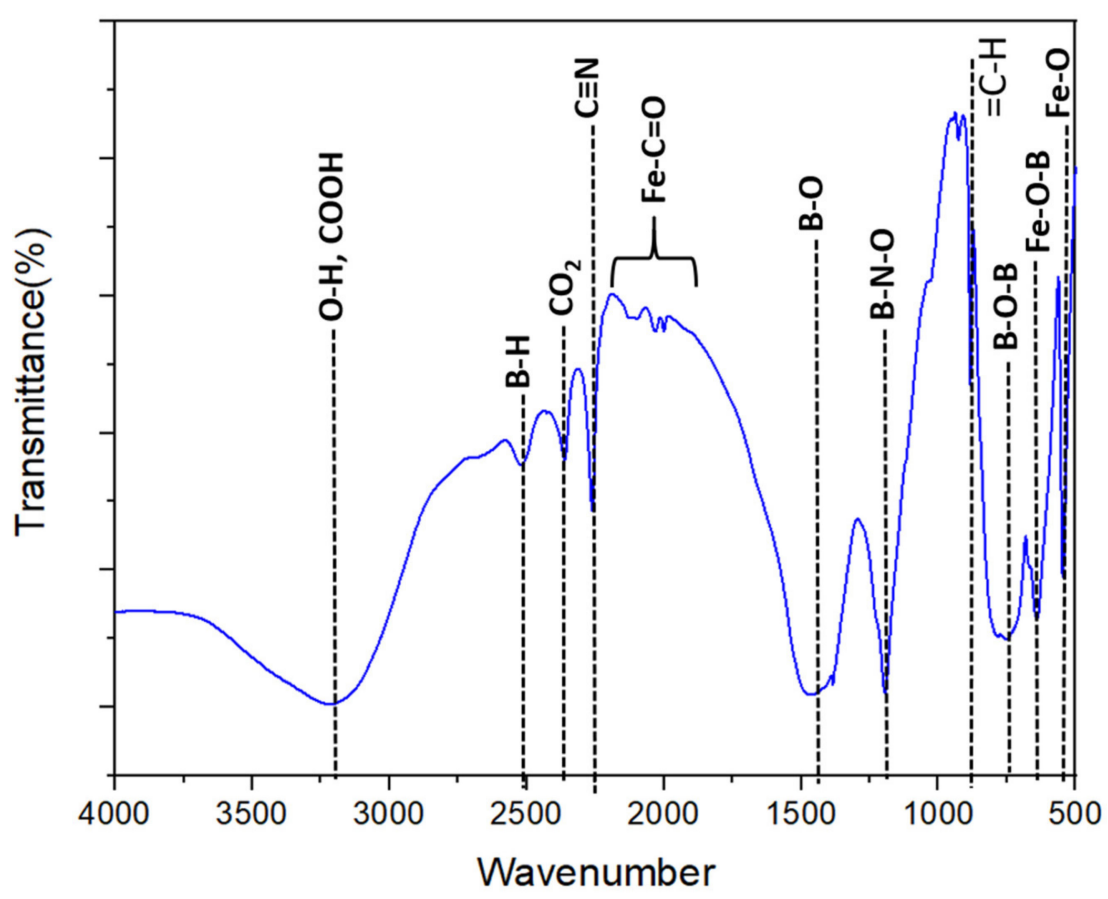

Figure 3. The FTIR spectrum of the as-prepared $\mathrm{C}, \mathrm{N}$-doped $\mathrm{FeBO}_{3}$.
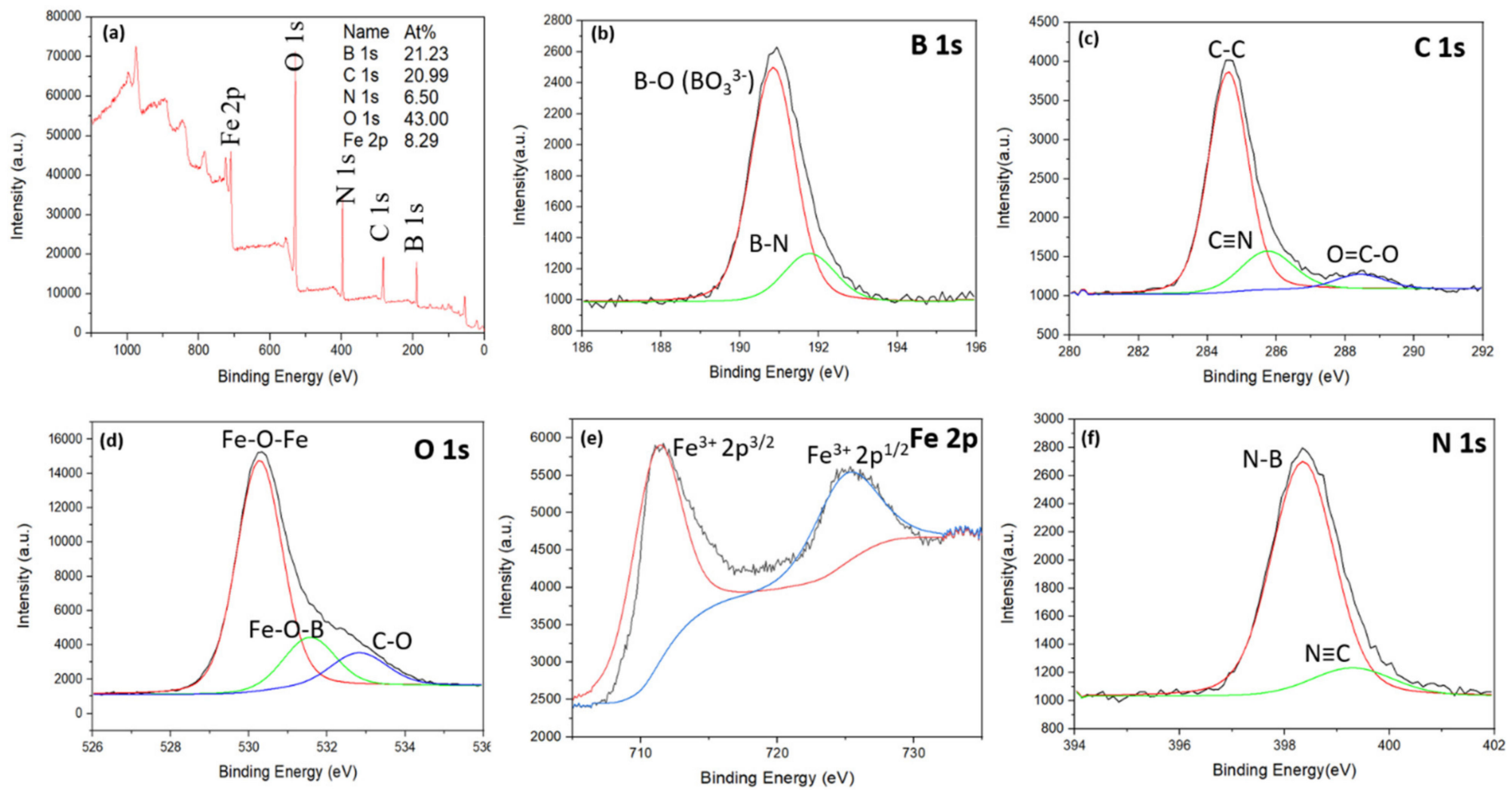

Figure 4. The XPS spectrum of the as-prepared C,N-doped $\mathrm{FeBO}_{3}$ : (a) full survey spectrum, (b-f) Gaussian fitted B 1s (b), C 1s (c), O 1s (d), Fe 2p (e), and N 1s (f) spectra.

To gain a deeper insight into the boron, carbon, nitrogen, and iron-related chemical bonding, the Gaussian fitted high-resolution XPS spectra $\left(R^{2}>0.99\right)$ are presented in Figure $4 b-f$. Thus, the $B$ 1s spectrum in Figure $4 \mathrm{~b}$ is composed of two fitted curves originating from the B-O bond at a binding energy of $190.8 \mathrm{eV}$ and the B-N-O bonds at $191.9 \mathrm{eV}[40,41]$. Similarly, the N 1 s spectrum (Figure $4 \mathrm{f}$ ) can be fitted with two Gaussian curves due to the N-B bonding at $398.3 \mathrm{eV}$ and the $\mathrm{N}-\mathrm{C}$ bonding at $399.2 \mathrm{eV}[33,42]$. Meanwhile, the $\mathrm{C} 1 \mathrm{~s}$ spectrum (Figure 4c) is composed of three peaks at 284.5, 285.7, and $288.1 \mathrm{eV}$ due to the $\mathrm{C}-\mathrm{C}, \mathrm{C}-\mathrm{N}$ 
and $\mathrm{C}-\mathrm{O}-\mathrm{C}$ species, respectively $[23,33]$. Taken together, the observed $\mathrm{B}-\mathrm{N}-\mathrm{O}, \mathrm{N}-\mathrm{B}$, and $\mathrm{C}-\mathrm{N}$ signals suggest that the $\mathrm{C}$ and $\mathrm{N}$ dopants are bonded to the borate anion within the $\mathrm{FeBO}_{3}$ crystal. Further, the $\mathrm{O} 1 \mathrm{~s}$ spectrum (Figure 4d) is deconvoluted into four peaks. The peaks at 530.2 and $531.1 \mathrm{eV}$ correspond to the $\mathrm{Fe}-\mathrm{O}-\mathrm{Fe}$ and $\mathrm{Fe}-\mathrm{O}-\mathrm{B}$ bonding, while that at $532.2 \mathrm{eV}$ corresponds to the $\mathrm{C}-\mathrm{O}$ bond [22]. The additional weak and broad peak could be due to the adsorbed $\mathrm{H}_{2} \mathrm{O}$ and $\mathrm{CO}_{2}$ under atmospheric conditions. Finally, the Fe $2 p$ spectrum reveals two peaks at 710.1 and $724.1 \mathrm{eV}$, which are attributed to the $\mathrm{Fe} 2 \mathrm{p}^{3 / 2}$ and $\mathrm{Fe} 2 \mathrm{p}^{1 / 2}$ of $\mathrm{FeBO}_{3}$, thus indicating the $\mathrm{Fe}^{3+}$ valence state [43].

The UV-DRS results for the heterogeneous $\mathrm{C}$,N-doped $\mathrm{FeBO}_{3}$ photo-Fenton catalysts with various weight percentages of iron nanoparticles are presented in Figure 4a. Here, each sample exhibits a broad absorbance in the visible region, and a large absorption band between 400 and $500 \mathrm{~nm}$. The corresponding Tauc plot of the sample with $5 \mathrm{wt} . \%$ iron nanoparticles in Figure $5 \mathrm{~b}$ indicates a bandgap of $2.5 \mathrm{eV}$, which is slightly lower than that of the pure $\mathrm{FeBO}_{3}(2.7 \mathrm{eV})$ [44]. This is consistent with the results of carbon and nitrogen doping into the frameworks of various nanomaterials [27] and favors the utilization of most of the solar spectrum by the as-prepared $\mathrm{C}, \mathrm{N}$-doped $\mathrm{FeBO}_{3}$ catalyst, thus contributing to an enhanced photo-Fenton activity. Further, the valence band edges of the vacuum levels derived from the secondary electron cutoff of the UPS spectra in Figure S2 indicate that the valence band position of the $\mathrm{C}, \mathrm{N}$-doped $\mathrm{FeBO}_{3}$ is $2.37 \mathrm{eV}$ versus the normal hydrogen electrode (NHE).
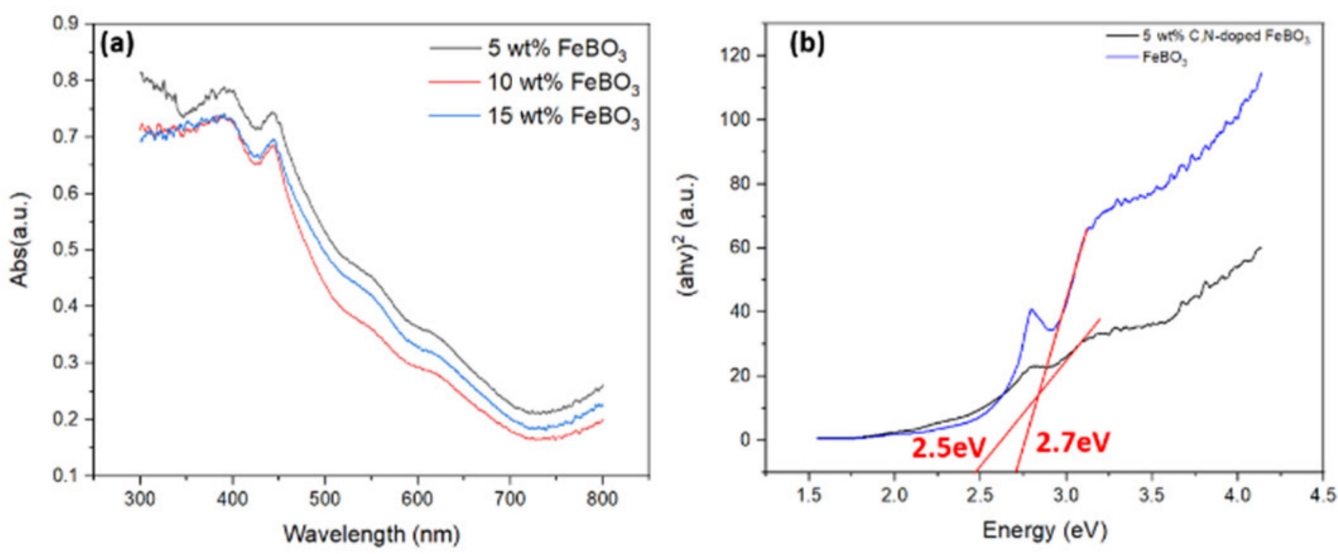

Figure 5. (a) The UV-DRS spectra of the $\mathrm{C}, \mathrm{N}$-doped $\mathrm{FeBO}_{3}$ with various iron contents, and (b) the Tauc plots of the $\mathrm{C}, \mathrm{N}$-doped $\mathrm{FeBO}_{3}$ with $5 \mathrm{wt}$.\% iron nanoparticles (black line) and the pristine $\mathrm{FeBO}_{3}$ (blue line).

\section{Photocatalytic Activity}

The photocatalytic room-temperature $\mathrm{MB}$ degradation curves of the pristine $\mathrm{Fe}_{3} \mathrm{O}_{4}$ nanoparticles and the $5 \mathrm{wt} . \% \mathrm{C}, \mathrm{N}$-doped $\mathrm{FeBO}_{3}$ particles in the presence and absence of hydrogen peroxide are presented in Figure 6a. Here, the $\mathrm{MB}$ does not undergo significant self-decomposition under visible light during the 20 min period in the presence of $\mathrm{H}_{2} \mathrm{O}_{2}$ only (black line). However, in the presence of the pristine 50-nm $\mathrm{Fe}_{3} \mathrm{O}_{4}$ nanoparticles and $\mathrm{H}_{2} \mathrm{O}_{2}$ (red line), only $25 \%$ of the $\mathrm{MB}$ is degraded within $20 \mathrm{~min}$ under the prescribed photo-Fenton reaction conditions. Moreover, the highest catalytic activity is indicated for the 5 wt.\% $\mathrm{C}, \mathrm{N}$-doped $\mathrm{FeBO}_{3}$ in the presence of $\mathrm{H}_{2} \mathrm{O}_{2}$ (blue line), with a degradation rate constant of $0.462 \mathrm{~min}^{-1}$ in the first $5 \mathrm{~min}$, and complete MB degradation by $20 \mathrm{~min}$ (Figure S3). 

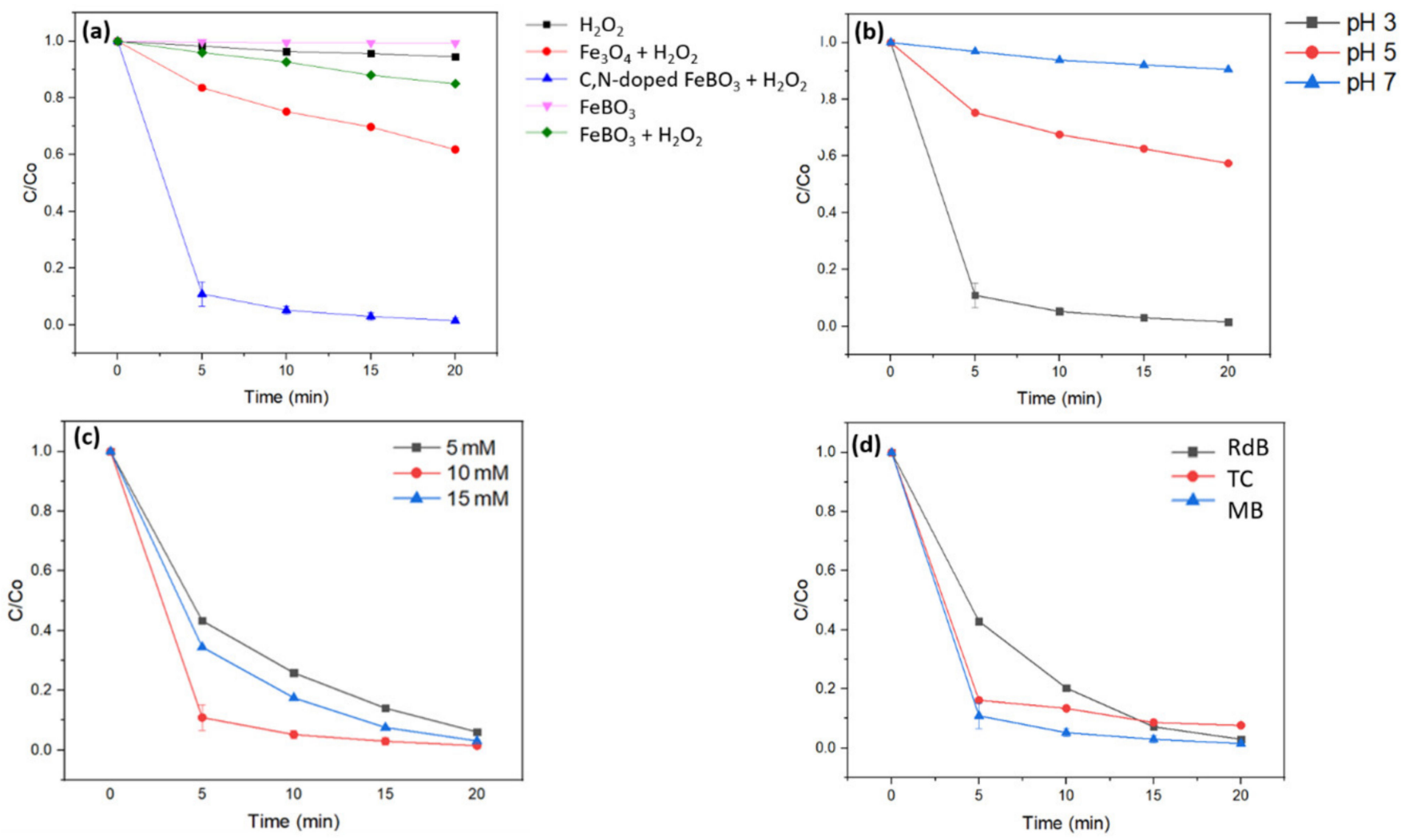

Figure 6. The MB degradation curves under simulated A.M 1.5 solar illumination for (a) the 5 wt.\% photo-Fenton catalysts in the presence and absence of $\mathrm{H}_{2} \mathrm{O}_{2}$, (b) the 5 wt. $\%$ C,N-doped $\mathrm{FeBO}_{3}$ and $\mathrm{H}_{2} \mathrm{O}_{2}$ at various $\mathrm{pH}$ values, (c) the 5 wt. $\%$,, $\mathrm{N}$-doped $\mathrm{FeBO}_{3}$ and $\mathrm{H}_{2} \mathrm{O}_{2}$ at various $\mathrm{H}_{2} \mathrm{O}_{2}$ concentrations, and (d) the photo-Fenton degradation activities for different pollutants using the $5 \mathrm{wt} . \% \mathrm{C}$,N-doped iron borate catalyst $\left(\mathrm{pH}=3, \mathrm{H}_{2} \mathrm{O}_{2}\right.$ concentration $=10 \mathrm{mM}$, pollutant concentration $\left.=10 \mathrm{ppm}\right)$.

Under the same photo-Fenton conditions, the pure $\mathrm{FeBO}_{3}$ synthesized according to literature [45] exhibits only $16 \% \mathrm{MB}$ degradation after $20 \mathrm{~min}$ (green line, Figure 6a, synthesis of pure $\mathrm{FeBO}_{3}$ is available in the Supplementary Materials). As a proof of concept demonstration, the photo-Fenton oxidation of other common pollutants such as tetracycline and Rhodamine B using the as prepared $5 \mathrm{wt} . \% \mathrm{C}, \mathrm{N}-$ doped iron borate achieved $92 \%$ and $100 \%$ degradation efficiency, respectively (Figure 6d). Thus, compared to other iron-based photo-Fenton catalysts, the as-prepared $5 \mathrm{wt} . \% \mathrm{C}, \mathrm{N}$-doped $\mathrm{FeBO}_{3}$ is a superior photoFenton catalyst with a potential of removing major organic pollutants with high efficiency during wastewater treatment. These results demonstrate that the carbon and nitrogen doping of $\mathrm{FeBO}_{3}$ plays a critical role in creating electrically charged sites, thus explaining the marked increase in the photocatalytic activity of the $\mathrm{C}, \mathrm{N}$-doped $\mathrm{FeBO}_{3}$ compared to their non-doped counterpart. Moreover, in the absence of $\mathrm{H}_{2} \mathrm{O}_{2}$, the $\mathrm{C}$, N-doped $\mathrm{FeBO}_{3}$ particles fail to degrade MB (purple line, Figure 6a), thus indicating that the main catalytic mechanism is the Fenton reaction.

In summary, the present study has demonstrated that the novel $\mathrm{C}$,N-doped $\mathrm{FeBO}_{3}$ catalyst exhibits 10- and 26-fold enhancements in photo-Fenton activity compared to that of the $\mathrm{Fe}_{3} \mathrm{O}_{4}$ nanoparticles alone and that of the non-doped $\mathrm{FeBO}_{3}$, respectively, under simulated solar irradiation. Further, the present study has demonstrated that the asprepared $\mathrm{C}, \mathrm{N}$-doped $\mathrm{FeBO}_{3}$ catalysts exhibit high pseudo first-order kinetic rates compared to those of other recently-reported catalysts, as summarized in Table S2.

The ICP-OES analyses of the $\mathrm{C}, \mathrm{N}$-doped $\mathrm{FeBO}_{3}$ samples prepared with various proportions of $\mathrm{Fe}_{3} \mathrm{O}_{4}$ nanoparticles are presented in Table S3, where the percentage of $\mathrm{Fe}$ in the final product is seen to match the weight percent of $\mathrm{Fe}_{3} \mathrm{O}_{4}$ nanoparticle added to the precursor mixtures. The $\mathrm{MB}$ degradation efficiency of the $\mathrm{C}, \mathrm{N}$-doped $\mathrm{FeBO}_{3}$ samples with various proportions of iron nanoparticles decreases with increasing Fe content as shown 
in Figure S4. The iron content of the $\mathrm{C}, \mathrm{N}$-doped $\mathrm{FeBO}_{3}$ is essential to the photo Fenton system. Generally, a higher iron content represents a larger number of redox active sites for generating ROS for the degradation of pollutants. However, an excessive iron content could also generate recombination centers for the photogenerated holes and electrons, thus removing the photocarriers that would otherwise assist in the photo-Fenton reaction [42].

In view of these results, the most active $5 \mathrm{wt} . \% \mathrm{C}$, N-doped $\mathrm{FeBO}_{3}$ was used in further investigations to determine the optimal photo-Fenton reaction $\mathrm{pH}$ conditions, as shown in Figure 6b. Thus, as with the majority of iron-based Fenton catalysts, the C,N-doped $\mathrm{FeBO}_{3}$ exhibits the highest Fenton activity at $\mathrm{pH}$. However, the degradation rate of the $5 \mathrm{wt} . \% \mathrm{C}, \mathrm{N}$-doped iron borate under this optimal condition is superior to that of most other Fenton catalysts, as shown in Table S2. Furthermore, the results in Figure 6 demonstrate that the quantitative degradation of $\mathrm{MB}$ dye can be achieved in $20 \mathrm{~min}$ in the presence of a minimal amount of $\mathrm{H}_{2} \mathrm{O}_{2}(\sim 320$ mole equivalent with respect to the concentration of pollutant). In addition, the $\mathrm{MB}$ degradation rates of the $5 \mathrm{wt} . \% \mathrm{C}, \mathrm{N}$-doped iron borate in the presence of various concentrations of $\mathrm{H}_{2} \mathrm{O}_{2}(5,10$, and $15 \mathrm{mM})$ are presented in Figure $6 \mathrm{c}$. Interestingly, a higher concentration of $\mathrm{H}_{2} \mathrm{O}_{2}$ is seen to result in a lower degradation rate during the initial period due to the competitive scavenging effect of the excess $\mathrm{H}_{2} \mathrm{O}_{2}$, as described previously. Finally, the MB degradation rates of the $5 \mathrm{wt} . \% \mathrm{C}, \mathrm{N}$-doped iron borate under illumination and in the dark are compared in Figure S5. Remarkably, 75\% MB degradation is achieved in 20 min even under dark conditions. Thus, it is believed that this proof-of-concept demonstration will facilitate the development of a new class of iron borate materials as efficient Fenton catalysts for water treatment applications both under sunlight and in the dark.

The stability and reusability of the as-prepared $\mathrm{C}, \mathrm{N}$-doped $\mathrm{FeBO}_{3}$ are shown in Figure 7, where the photo-Fenton efficiency remained quantitative after three successive cycling runs. The concentrations of $\mathrm{MB}$ and $\mathrm{H}_{2} \mathrm{O}_{2}$ in the subsequent photo-Fenton oxidation reactions were adjusted accordingly to accommodate for the loss of catalyst during the repeated washing and filtration. Moreover, the $\mathrm{C}, \mathrm{N}$-doped iron borate exhibits remarkable stability under the prescribed photo-Fenton condition (simulated solar light, $\mathrm{pH} 3$ ) as evidenced by the low iron concentration in solution after 20 and $60 \mathrm{~min}$ of dye degradation reaction (Table S4). Furthermore, the XRD diffraction patterns of the recovered solid catalyst obtained after the photo-Fenton reaction (Figure S6) are seen to be identical to those of the pristine, as-prepared C,N-doped iron borate in Figure 1, thus indicating that the catalyst is stable and can withstand photocorrosion under the simulated solar irradiation.

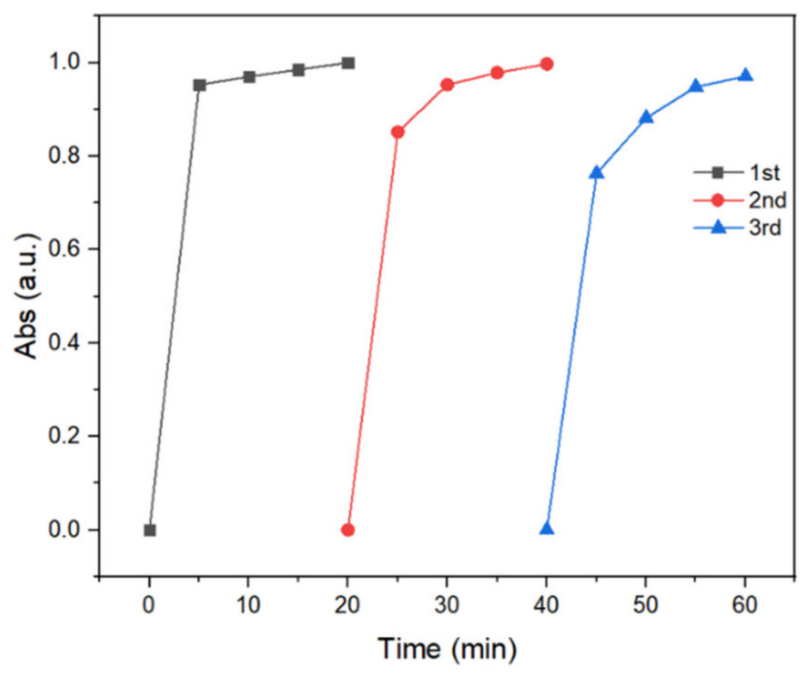

Figure 7. MB dye degradation efficiency of using $\mathrm{C}, \mathrm{N}$-doped $\mathrm{FeBO}_{3}$ for consecutive three experiments. The mass of catalyst used was $50 \mathrm{mg}, 16 \mathrm{mg}$, and $9 \mathrm{mg}$, respectively. 
The dominant ROS species contributing to the photo-Fenton activity of the C,Ndoped $\mathrm{FeBO}_{3}$ catalyst are revealed by the selective trapping results in Figure 8. Here, the photo-Fenton activity is seen to be significantly suppressed upon the addition of the $\cdot \mathrm{OH}$ scavenger isopropanol [46] thus indicating that the main ROS responsible for the degradation of MB is the hydroxyl radical. Meanwhile, the $\mathrm{h}^{+}$and $\mathrm{O}_{2}{ }^{-}$superoxide species play secondary and tertiary roles, respectively, in the photo-Fenton reaction. Thus, as revealed by the purple line in Figure $6 \mathrm{a}$, the $\mathrm{C}, \mathrm{N}$-doped $\mathrm{FeBO}_{3}$ shows no photocatalytic activity in the absence of $\mathrm{H}_{2} \mathrm{O}_{2}$. Under photo-Fenton conditions, however, the photogenerated charge carrier is rapidly injected into the $\mathrm{Fe}^{3+}$ site to form the redox-active $\mathrm{Fe}^{2+}$ while generating ROS via the reaction with $\mathrm{H}_{2} \mathrm{O}_{2}$. The resulting rapid consumption of photogenerated electrons enables the photogenerated holes to also participate in the MB dye degradation.

(a)

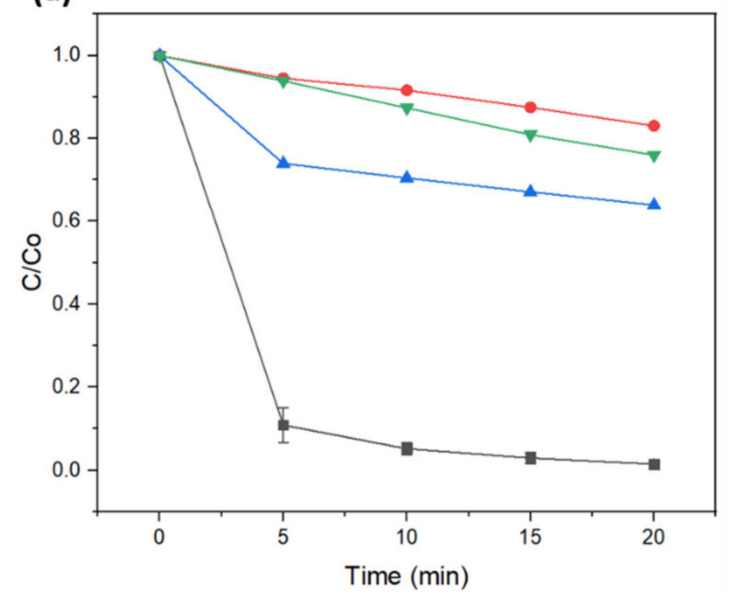

(b)

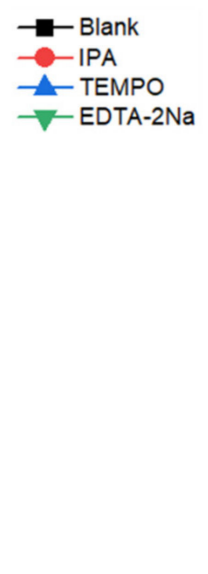

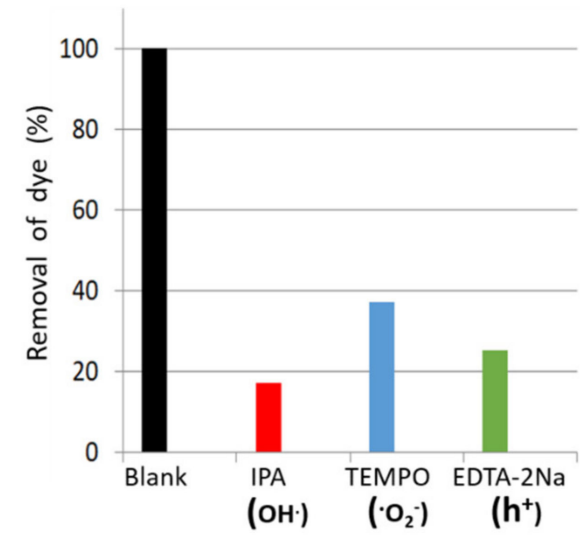

Figure 8. (a) The photodegradation of $\mathrm{MB}$ by the as-prepared $\mathrm{C}, \mathrm{N}$-doped $\mathrm{FeBO}_{3}$ under simulated solar illumination in the presence of various scavengers: (a) a plot of $\mathrm{C} / \mathrm{Co}$; (b) a bar graph showing the percentage removal of $\mathrm{MB}$.

The role of $\cdot \mathrm{OH}$ as the dominant ROS species in the photo-Fenton system is further verified by the use of terephthalic acid as a hydroxyl radical probe. Thus, in Figure 9, the fluorescence intensity of 2-hydroxyphthatlic acid directly corresponds to the concentration of hydroxyl radicals formed during the Fenton reaction [47]. As anticipated, a much higher concentration of hydroxyl radical is produced under the simulated solar irradiation than in the dark, thus explaining the slightly higher degradation efficiency under photo-Fenton conditions. In the dark, the $\mathrm{C}, \mathrm{N}$-doped $\mathrm{FeBO}_{3}$ is also capable of producing a significant amount of hydroxyl radical, commensurate with the observed dark-Fenton activity in Figure 9. This result demonstrates that the as-prepared $\mathrm{C}, \mathrm{N}$-doped $\mathrm{FeBO}_{3}$ will be able to operate continuously with a high degradation efficiency both in the presence and absence of sunlight, thus reducing the overall amount of time needed to treat a particular batch of wastewater. Furthermore, these catalysts open up the possibility of treating waste water in areas that do not receive sufficient sunlight.

The above-mentioned controlled and trapping experiments demonstrate that the dye degradation mechanism of the $\mathrm{C}, \mathrm{N}$-doped $\mathrm{FeBO}_{3}$ follows the standard Fenton reaction. As shown schematically in Figure 10, the peculiar activity of the C,N-doped $\mathrm{FeBO}_{3}$ catalyst in Fenton reactions might be explained by the synergistic effect of the negatively-charged borate ligands $[48,49]$. According to in-depth studies of metal borates as electrocatalysts, the borate ligands serve as sacrificial ligands for the formation of a redox-active metal site via a reverse electron transfer mechanism. As a result, the iron center is filled with more electrons and, thus, can readily be reduced to form the redox-active $\mathrm{Fe}^{2+}$. In addition, the negativelycharged borate ligand serves as a preferential adsorption site for $\mathrm{MB}$ and $\mathrm{H}_{2} \mathrm{O}_{2} / \mathrm{H}_{2} \mathrm{O}$, which consequently shortens the charge transfer distance between the $\mathrm{Fe}^{2+} / \mathrm{Fe}^{3+}$ and $\mathrm{H}_{2} \mathrm{O}_{2}$ to produce the reactive hydroxyl radicals [50]. Under photo-Fenton conditions, a $25 \%$ increase in Fenton activity could be attributed to the injection of the photogenerated electrons into 
the $\mathrm{Fe}^{2+} / \mathrm{Fe}^{3+}$ site. Based on the band gap and band edge analysis of the $\mathrm{C}, \mathrm{N}$-doped $\mathrm{FeBO}_{3}$, the conduction band is located at $-0.17 \mathrm{eV}$ vs. NHE, while the $\mathrm{Fe}^{3+} / \mathrm{Fe}^{2+}$ redox potential is at $0.77 \mathrm{eV}$. The more negative conduction band of the $\mathrm{C}, \mathrm{N}$-doped $\mathrm{FeBO}_{3}$ allows the direct injection of the photogenerated electrons into the $\mathrm{Fe}^{3+} / \mathrm{Fe}^{2+}$ cycle to overcome the rate limiting step of the Fenton reaction.

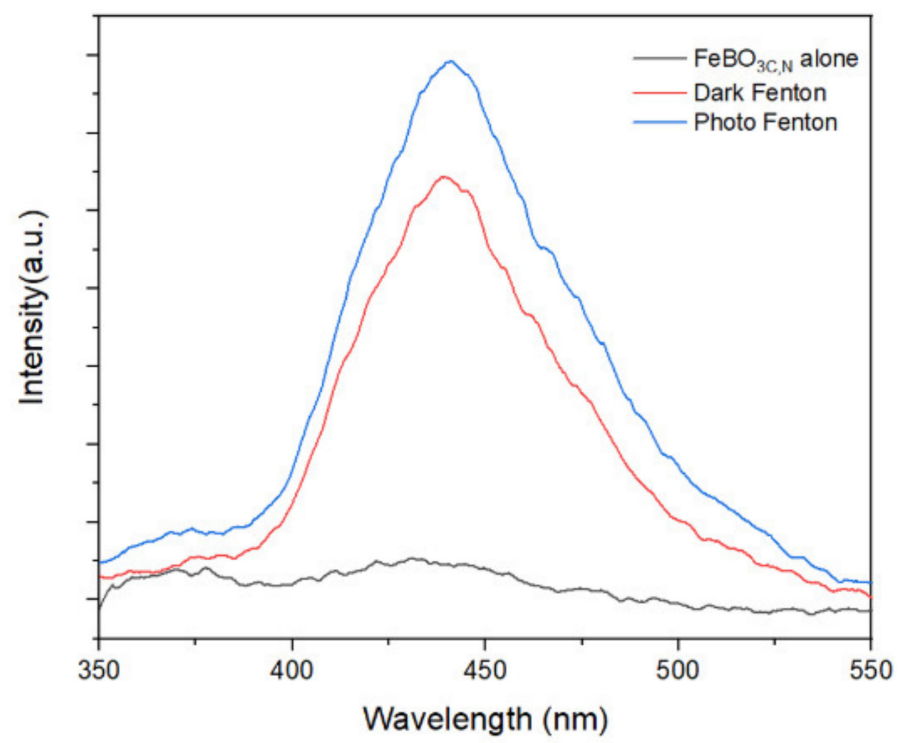

Figure 9. The $\mathrm{TAOH}$ fluorescence spectra of the $\mathrm{C}, \mathrm{N}$-doped $\mathrm{FeBO}_{3}$ alone under the dark-Fenton reaction and photo-Fenton reaction for $20 \mathrm{~min}$.

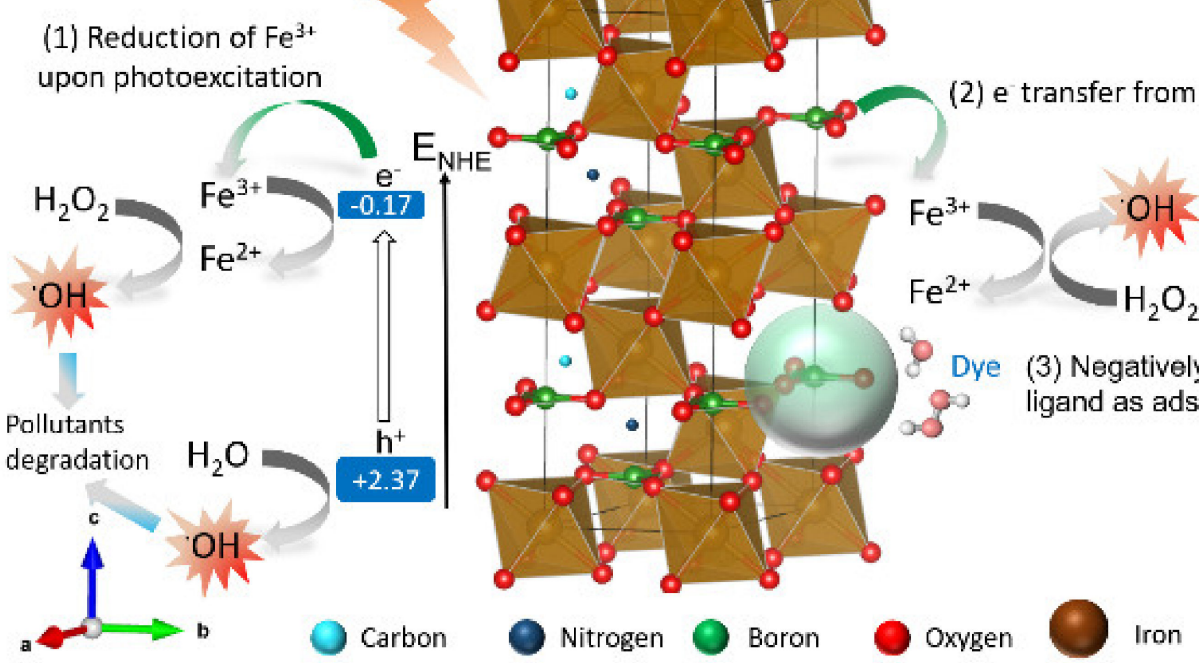

Figure 10. A schematic diagram showing the unit cell of $\mathrm{C}, \mathrm{N}$-doped $\mathrm{FeBO}_{3}$ and the proposed mechanism of $\mathrm{MB}$ degradation on the $\mathrm{C}, \mathrm{N}$-doped $\mathrm{FeBO}_{3}$ system. The aqua blue spheres-carbon, blue-nitrogen, green-boron, red-oxygen, and brown-iron. 
Meanwhile, the photogenerated holes $\left(\mathrm{h}^{+}\right)$that are formed at the highly positive valence band of the $\mathrm{C}$,N-doped $\mathrm{FeBO}_{3}$ could directly oxidize the adsorbed water or hydroxyl anion to produce the reactive radical via the reactions in Equations (1) and (2):

$$
\begin{gathered}
\mathrm{h}^{+}+\mathrm{OH}^{-} \rightarrow \mathrm{OH}(1.99 \mathrm{eV} \text { vs. NHE }) \\
\mathrm{h}^{+}+\mathrm{H}_{2} \mathrm{O} \rightarrow \cdot \mathrm{OH}+\mathrm{H}^{+}(2.27 \mathrm{eV} \text { vs. NHE })
\end{gathered}
$$

Furthermore, the carbon and nitrogen doping of the $\mathrm{FeBO}_{3}$ plays a critical role in the 26-fold enhancement in the Fenton activity relative to that of the non-doped $\mathrm{FeBO}_{3}$. Carbon, nitrogen, and boron dopants are commonly used for improving the catalytic activity of various catalysts. For example, nitrogen-doped catalysts generally show an increase in the number of catalytic sites along with improved adsorption of active species, thus facilitating the electric conductivity by providing electron carriers and decreasing the band gap energies [51]. As shown in Figure 5b, the bandgap of the $\mathrm{C}, \mathrm{N}$-doped $\mathrm{FeBO}_{3}$ is smaller than that of the un-doped $\mathrm{FeBO}_{3}$, which is consistent with the effect of carbon and nitrogen in modulating the electronic properties of other catalysts. Although further in operando investigations are needed in order to elucidate the mechanism of $\mathrm{FeBO}_{3}$ in promoting the Fenton activity, this initial proof-of-concept helps to provide a basic understanding of the utilization of a new class of iron materials as effective (photo)-Fenton catalysts.

\section{Conclusions}

In this study, a novel $\mathrm{C}, \mathrm{N}$-doped $\mathrm{FeBO}_{3}$ catalyst was synthesized via a simple and cost-effective method. The most optimal $\mathrm{C}, \mathrm{N}$-doped $\mathrm{FeBO}_{3}$ catalyst was prepared using 5 wt. $\% \mathrm{Fe}_{3} \mathrm{O}_{4}$ nanoparticles. The highest photo-Fenton activity was obtained using $10 \mathrm{mM}$ of $\mathrm{H}_{2} \mathrm{O}_{2}$ in $10 \mathrm{ppm}$ concentration of $\mathrm{MB}$ dye at $\mathrm{pH}$ 3. Moreover, the as prepared catalyst was shown to remove various organic pollutants with high efficiency under simulated solar light irradiation. Based on the band edges of the $\mathrm{C}, \mathrm{N}$-doped $\mathrm{FeBO}_{3}$, the photogenerated electrons can be directly injected into the $\mathrm{Fe}^{3+} / \mathrm{Fe}^{2+}$ site, thus increasing the Fenton activity upon solar irradiation. The facile Fenton activity of $\mathrm{FeBO}_{3}$ could be attributed to the synergistic effects of the borate ligand and the metal center of the $\mathrm{FeBO}_{3}$ framework. Furthermore, the carbon and nitrogen dopants effectively modified the electronic structure, facilitated charge transport, and increased the conductivity, thus contributing to the excellent catalytic activity over the non-doped $\mathrm{FeBO}_{3}$. This study provides a simple and facile methodology for the preparation of a highly stable and active single component, metal borate-based photo-Fenton catalyst capable of absorbing visible light that could potentially bridge the gap between academic research and industrial application in wastewater remediation.

Supplementary Materials: The following are available online at https:/ / www.mdpi.com/article/10 $.3390 /$ nano11112853/s1: Synthesis of the pure iron borate; Figure S1: XPS full spectra with fitting curves of (a) $\mathrm{FeBO}_{3}$ and (b) $\mathrm{C}, \mathrm{N}$-doped $\mathrm{FeBO}_{3}$, Figure S2. UPS spectra of $\mathrm{C}, \mathrm{N}$-doped $\mathrm{FeBO}_{3}$, Figure S3. Pseudo-first-order rate reaction kinetics for $\mathrm{MB}$ dye with different condition; Figure S4: Degradation curves of methylene blue under A.M 1.5 solar simulator using different iron content $\mathrm{C}, \mathrm{N}$-doped $\mathrm{FeBO}_{3}$ $+\mathrm{H}_{2} \mathrm{O}_{2}$ as photo-Fenton catalyst; Figure S5. The comparative MB photodegradation performance of the 5 wt.\% C,N-doped $\mathrm{FeBO}_{3}$ in the dark and under illumination; Figure S6. The comparison of XRD pattern before and after photocatalytic experiment. Table S1: XPS elemental composition of the 5 wt. \% C,N-doped $\mathrm{FeBO}_{3}$; Table S2. Representative works of other photo-Fenton catalysts and their efficiency in the degradation of methylene blue dye at $\mathrm{pH}$ 3; Table S3. ICP-OES of the solid $\mathrm{C}, \mathrm{N}$-doped $\mathrm{FeBO}_{3}$ prepared using different weight percentage of $\mathrm{Fe}_{3} \mathrm{O}_{4}$ nanoparticles; Table S4. Quantitative measurement of iron concentration leached out into the solution after 20.

Author Contributions: S.-Y.H.--Investigation, methodology, formal analysis, writing original draft. E.-X.L.-Investigation. P.-Y.K.-Conceptualization, funding acquisition, methodology, resources, supervision, validation, visualization, writing — review and editing. All authors have read and agreed to the published version of the manuscript. 
Funding: This work was funded by Ministry of Science and Technology Taiwan (MOST 108-2113-M007-030).

Conflicts of Interest: The authors declare no conflict of interest.

\section{References}

1. Gupta, V.K.; Ali, I.; Saleh, T.A.; Nayak, A.; Agarwal, S. Chemical treatment technologies for waste-water recycling-An overview. RSC Adv. 2012, 2, 6380. [CrossRef]

2. Mandal, T.; Maity, S.; Dasgupta, D.; Datta, S. advanced oxidation process and biotreatment: Their roles in combined industrial wastewater treatment. Desalination 2010, 250, 87-94. [CrossRef]

3. Thomas, N.; Dionysiou, D.D.; Pillai, S.C. Heterogeneous Fenton catalysts: A review of recent advances. J. Hazard. Mater. 2021, 404, 124082. [CrossRef] [PubMed]

4. Pignatello, J.J.; Oliveros, E.; MacKay, A. Advanced oxidation processes for organic contaminant destruction based on the fenton reaction and related chemistry. Crit. Rev. Environ. Sci. Technol. 2006, 36, 1-84. [CrossRef]

5. Zhu, Y.; Zhu, R.; Xi, Y.; Zhu, J.; Zhu, G.; He, H. Strategies for enhancing the heterogeneous fenton catalytic reactivity: A review. Appl. Catal. B Environ. 2019, 255, 117739. [CrossRef]

6. Brillas, E.; Sirés, I.; Oturan, M.A. Electro-fenton process and related electrochemical technologies based on Fenton's reaction chemistry. Chem. Rev. 2009, 109, 6570-6631. [CrossRef]

7. Bauer, R. The photo-fenton reaction and the TiO2/UV process for waste water treatment-Novel developments. Catal. Today 1999, 53, 131-144. [CrossRef]

8. Giannakis, S.; López, M.I.P.; Spuhler, D.; Pérez, J.A.S.; Ibáñez, P.F.; Pulgarin, C. Solar disinfection is an augmentable, in situgenerated photo-fenton reaction-Part 2: A review of the applications for drinking water and wastewater disinfection. Appl. Catal. B Environ. 2016, 198, 431-446. [CrossRef]

9. Lamb, J.J.; Islam, M.H.; Hjelme, D.R.; Pollet, B.G.; Lien, K.M. Effect of power ultrasound and fenton reagents on the biomethane potential from steam-exploded birchwood. Ultrason. Sonochem. 2019, 58, 104675. [CrossRef]

10. Ning, X.; Chen, H.; Wu, J.; Wang, Y.; Liu, J.; Lin, M. Effects of ultrasound assisted fenton treatment on textile dyeing sludge structure and dewaterability. Chem. Eng. J. 2014, 242, 102-108. [CrossRef]

11. Liu, Q.; Zhou, L.; Liu, L.; Li, J.; Wang, S.; Znad, H.; Liu, S. Magnetic ZnO@ $\mathrm{Fe}_{3} \mathrm{O}_{4}$ composite for self-generated $\mathrm{H}_{2} \mathrm{O}_{2}$ toward photo-fenton-like oxidation of nitrophenol. Compos. Part B Eng. 2020, 200, 108345. [CrossRef]

12. Sun, Q.; Hong, Y.; Liu, Q.; Dong, L. Synergistic operation of photocatalytic degradation and fenton process by magnetic $\mathrm{Fe}_{3} \mathrm{O}_{4}$ loaded $\mathrm{TiO}_{2}$. Appl. Surf. Sci. 2018, 430, 399-406. [CrossRef]

13. Lee, S.-Y.; Park, S.-J. $\mathrm{TiO}_{2}$ photocatalyst for water treatment applications. J. Ind. Eng. Chem. 2013, 19, 1761-1769. [CrossRef]

14. Tian, C.; Zhang, Q.; Wu, A.; Jiang, M.; Liang, Z.; Jiang, B.; Fu, H. Cost-effective large-scale synthesis of ZnO photocatalyst with excellent performance for dye photodegradation. Chem. Commun. 2012, 48, 2858. [CrossRef] [PubMed]

15. Gao, X.; Ma, C.; Liu, Y.; Xing, L.; Yan, Y. Self-induced fenton reaction constructed by Fe(III) grafted BiVO 4 nanosheets with improved photocatalytic performance and mechanism insight. Appl. Surf. Sci. 2019, 467-468, 673-683. [CrossRef]

16. Huang, T.; Zhu, J.; Ge, S.; Guo, T.; Jiang, C.; Xie, L. Synthesis of novel CdSe QDs/BiFeO 3 composite catalysts and its application for the photo-fenton catalytic degradation of phenol. J. Environ. Chem. Eng. 2020, 8, 104384. [CrossRef]

17. Ma, J.; Yang, Q.; Wen, Y.; Liu, W. Fe-g-C3N4/graphitized mesoporous carbon composite as an effective fenton-like catalyst in a wide PH range. Appl. Catal. B Environ. 2017, 201, 232-240. [CrossRef]

18. Diehl, R. Crystal structure refinement of ferric borate, $\mathrm{FeBO}_{3}$. Solid State Commun. 1975, 17, 743-745. [CrossRef]

19. Joubert, J.C.; Shirk, T.; White, W.B.; Roy, R. Stability, infrared spectrum and magnetic properties of FeBO 3 . Mater. Res. Bull. 1968, 3, 671-676. [CrossRef]

20. Yagupov, S.; Strugatsky, M.; Seleznyova, K.; Mogilenec, Y.; Snegirev, N.; Marchenkov, N.V.; Kulikov, A.G.; Eliovich, Y.A.; Frolov, K.V.; Ogarkova, Y.L.; et al. Development of a synthesis technique and characterization of high-quality iron borate $\mathrm{FeBO}_{3}$ single crystals for applications in synchrotron technologies of a new generation. Cryst. Growth Des. 2018, 18, 7435-7440. [CrossRef]

21. Dastafkan, K.; Li, Y.; Zeng, Y.; Han, L.; Zhao, C. Enhanced surface wettability and innate activity of iron borate catalyst for efficient oxygen evolution and gas bubble detachment. J. Mater. Chem. A 2019, 7, 15252-15261. [CrossRef]

22. Zhao, W.; Xu, T.; Li, T.; Wang, Y.; Liu, H.; Feng, J.; Ding, S.; Li, Z.; Wu, M. Amorphous iron(III)-borate nanolattices as multifunctional electrodes for self-driven overall water splitting and rechargeable zinc-air battery. Small 2018, 14, 1802829. [CrossRef]

23. Huang, C.; Chen, C.; Zhang, M.; Lin, L.; Ye, X.; Lin, S.; Antonietti, M.; Wang, X. Carbon-doped BN nanosheets for metal-free photoredox catalysis. Nat. Commun. 2015, 6, 7698. [CrossRef]

24. Jia, Y.; Wu, C.; Kim, D.-H.; Lee, B.W.; Rhee, S.J.; Park, Y.C.; Kim, C.S.; Wang, Q.J.; Liu, C. Nitrogen doped BiFeO 3 with enhanced magnetic properties and photo-fenton catalytic activity for degradation of bisphenol a under visible light. Chem. Eng. J. 2018, 337, 709-721. [CrossRef]

25. Yao, Y.; Chen, H.; Qin, J.; Wu, G.; Lian, C.; Zhang, J.; Wang, S. Iron encapsulated in boron and nitrogen codoped carbon nanotubes as synergistic catalysts for fenton-like reaction. Water Res. 2016, 101, 281-291. [CrossRef]

26. Yu, J.; Chen, Z.; Zeng, L.; Ma, Y.; Feng, Z.; Wu, Y.; Lin, H.; Zhao, L.; He, Y. Synthesis of carbon-doped $\mathrm{KNbO}_{3}$ photocatalyst with excellent performance for photocatalytic hydrogen production. Sol. Energy Mater. Sol. Cells 2018, 179, 45-56. [CrossRef] 
27. Zhou, H.; Wu, S.; Zhou, Y.; Yang, Y.; Zhang, J.; Luo, L.; Duan, X.; Wang, S.; Wang, L.; Tsang, D.C.W. Insights into the oxidation of organic contaminants by iron nanoparticles encapsulated within boron and nitrogen co-doped carbon nanoshell: Catalyzed fenton-like reaction at natural PH. Environ. Int. 2019, 128, 77-88. [CrossRef]

28. Ogi, T.; Iwasaki, H.; Nandiyanto, A.B.D.; Iskandar, F; Wang, W.-N.; Okuyama, K. Direct white light emission from a rare-earth-free aluminium-boron-carbon-oxynitride phosphor. J. Mater. Chem. C 2014, 2, 4297-4303. [CrossRef]

29. Sun, Y.; Ma, M.; Zhang, Y.; Gu, N. Synthesis of nanometer-size maghemite particles from magnetite. Colloids Surf. A Physicochem. Eng. Asp. 2004, 245, 15-19. [CrossRef]

30. Das, S.K.; Nandi, M.; Giri, S.; Bhaumik, A. A new mesoporous $\mathrm{FeBO}_{3}$ material having dominant surface magnetism. Microporous Mesoporous Mater. 2009, 117, 362-367. [CrossRef]

31. Kumari, K.; Ram, S.; Kotnala, R.K. Self-controlled growth of $\mathrm{Fe}_{3} \mathrm{BO}_{6}$ crystallites in shape of nanorods from iron-borate glass of small templates. Mater. Chem. Phys. 2011, 129, 1020-1026. [CrossRef]

32. Singh, B.; Kaur, G.; Singh, P.; Singh, K.; Kumar, B.; Vij, A.; Kumar, M.; Bala, R.; Meena, R.; Singh, A.; et al. Nanostructured boron nitride with high water dispersibility for boron neutron capture therapy. Sci. Rep. 2016, 6, 35535. [CrossRef]

33. Sudeep, P.M.; Vinod, S.; Ozden, S.; Sruthi, R.; Kukovecz, A.; Konya, Z.; Vajtai, R.; Anantharaman, M.R.; Ajayan, P.M.; Narayanan, T.N. Functionalized boron nitride porous solids. RSC Adv. 2015, 5, 93964-93968. [CrossRef]

34. Zhang, C.C.; Gao, X.; Yilmaz, B. Development of FTIR spectroscopy methodology for characterization of boron species in FCC catalysts. Catalysts 2020, 10, 1327. [CrossRef]

35. Yumura, T.; Amenomori, T.; Kagawa, Y.; Yoshizawa, K. Mechanism for the formaldehyde to formic acid and the formic acid to carbon dioxide conversions mediated by an iron-oxo species. J. Phys. Chem. A 2002, 106, 621-630. [CrossRef]

36. Busca, G.; Lorenzelli, V. Infrared study of $\mathrm{CO}_{2}$ adsorption on haematite. Mater. Chem. 1980, 5, 213-223. [CrossRef]

37. Liu, R.; Ma, Z.; Sears, J.D.; Juneau, M.; Neidig, M.L.; Porosoff, M.D. Identifying correlations in fischer-tropsch synthesis and $\mathrm{CO}_{2}$ hydrogenation over Fe-based ZSM-5 catalysts. J. CO2 Util. 2020, 41, 101290. [CrossRef]

38. Starobrat, A.; Jaroń, T.; Grochala, W. New hydrogen-rich ammonium metal borohydrides, NH4[M(BH4)4], M = Y, Sc, Al, as potential $\mathrm{H}_{2}$ sources. Dalton Trans. 2018, 47, 4442-4448. [CrossRef] [PubMed]

39. Kim, S.-K.; Hong, S.-A.; Son, H.-J.; Han, W.-S.; Michalak, A.; Hwang, S.-J.; Kang, S.O. Dehydrogenation of ammonia-borane by cationic $\mathrm{Pd}(\mathrm{II})$ and $\mathrm{Ni}(\mathrm{II})$ complexes in a nitromethane medium: Hydrogen release and spent fuel characterization. Dalton Trans. 2015, 44, 7373-7381. [CrossRef]

40. Fujisawa, K.; Cruz-Silva, R.; Yang, K.-S.; Kim, Y.A.; Hayashi, T.; Endo, M.; Terrones, M.; Dresselhaus, M.S. Importance of open, heteroatom-decorated edges in chemically doped-graphene for supercapacitor applications. J. Mater. Chem. A 2014, 2, 9532-9540. [CrossRef]

41. Kurmaev, E.; Fedorenko, V.; Galakhov, V.; Bartkowski, S.; Uhlenbrock, S.; Neumann, M.; Slater, P.; Greaves, C.; Miyazaki, Y. Analysis of oxyanion $\left(\mathrm{BO}_{3}{ }^{3-}, \mathrm{CO}_{3}{ }^{2-}, \mathrm{SO}_{4}{ }^{2-}, \mathrm{PO}_{4}{ }^{3-}, \mathrm{SeO}_{4}{ }^{4-}\right)$ substitution in $\mathrm{Y} 123$ compounds studied by X-ray photoelectron spectroscopy. J. Supercond. 1996, 9, 97-100. [CrossRef]

42. Hu, J.; Zhang, P.; An, W.; Liu, L.; Liang, Y.; Cui, W. In-situ Fe-doped g-C3N4 heterogeneous catalyst via photocatalysis-fenton reaction with enriched photocatalytic performance for removal of complex wastewater. Appl. Catal. B Environ. 2019, 245, 130-142. [CrossRef]

43. Yamashita, T.; Hayes, P. Analysis of XPS spectra of Fe2+ and Fe3+ ions in oxide materials. Appl. Surf. Sci. 2008, 254, 2441-2449. [CrossRef]

44. Lyubutin, I.; Sarkisyan, V.; Gavriliuk, A.; Troyan, I.; Rüffer, R. Hyperfine interactions and electronic structure of FeBO 3 at high pressure. Bull. Russ. Acad. Sci. Phys. 2003, 67, 1018.

45. Wu, B.; Qi, S.; Wu, X.; Wang, H.; Zhuang, Q.; Yi, H.; Xu, P.; Xiong, Z.; Shi, G.; Chen, S.; et al. FeBO 3 as a low cost and high-performance anode material for sodium-ion batteries. In press. Chin. Chem. Lett. 2021. [CrossRef]

46. Gao, J.; Liu, Y.; Xia, X.; Wang, L.; Shao, L.; Cai, T.; Dong, W. Mechanisms for photo assisted fenton of synthesized pyrrhotite at neutral PH. Appl. Surf. Sci. 2019, 463, 863-871. [CrossRef]

47. Bahrudin, N.N.; Nawi, M.A.; Nawawi, W.I. Photocatalytic enhancement of immobilized $\mathrm{TiO}_{2}$-polyaniline bilayer (TiO 2 -PBL) system for decolorization of methyl orange dye. Mater. Res. Bull. 2018, 106, 388-395. [CrossRef]

48. Huang, H.; He, Y.; Lin, Z.; Kang, L.; Zhang, Y. Two novel bi-based borate photocatalysts: Crystal structure, electronic structure, photoelectrochemical properties, and photocatalytic activity under simulated solar light irradiation. J. Phys. Chem. C 2013, 117, 22986-22994. [CrossRef]

49. Li, Y.; Diao, Y.; Wang, X.; Tian, X.; Hu, Y.; Zhang, B.; Yang, D. $\mathrm{Zn}_{4} \mathrm{~B}_{6} \mathrm{O}_{13}$ : Efficient borate photocatalyst with fast carrier separation for photodegradation of tetracycline. Inorg. Chem. 2020, 59, 13136-13143. [CrossRef]

50. Hu, X.; Li, R.; Zhao, S.; Xing, Y. Microwave-assisted preparation of flower-like cobalt phosphate and its application as a new heterogeneous fenton-like catalyst. Appl. Surf. Sci. 2017, 396, 1393-1402. [CrossRef]

51. Rajoriya, S.; Bargole, S.; George, S.; Saharan, V.K.; Gogate, P.R.; Pandit, A.B. Synthesis and characterization of samarium and nitrogen doped $\mathrm{TiO}_{2}$ photocatalysts for photo-degradation of 4-acetamidophenol in combination with hydrodynamic and acoustic cavitation. Sep. Purif. Technol. 2019, 209, 254-269. [CrossRef] 